\title{
Static Stiffness Modeling of Parallel Kinematics Machine Tool Joints
}

\author{
O. K. Akmaev, B. A. Enikeev* and A. I. Nigmatullin \\ Department of mechatronic machining systems, Ufa state aviation technical university, Ufa, Russia
}

Received 2 September 2015; Accepted 9 September 2015

\begin{abstract}
The possible variants of an original parallel kinematics machine-tool structure are explored in this article. A new Hooke's universal joint design based on needle roller bearings with the ability of a preload setting is proposed. The bearing stiffness modeling is carried out using a variety of methods. The elastic deformation modeling of a Hook's joint and a spherical rolling joint have been developed to assess the possibility of using these joints in machine tools with parallel kinematics.
\end{abstract}

Keywords: parallel kinematics, joints, milling machine-tool, stiffness, FEM analyses.

\section{Introduction}

In order to improve the efficiency of complex-surfaces machine parts processing, many of the leading machine tool companies are interested in high-speed machining technology (HSM) and are looking into the possibility of using it on parallel kinematics machines. One of the main reasons hindering the commercial use of parallel kinematics machines is their insufficient rigidity. Thus, analysis of studies evaluating parallel kinematics machines stiffness have revealed that the stiffness of the existing machines with parallel kinematics ranges from 5 to $200 \mathrm{~N} / \mathrm{um}$ which is lower than the respective values of classic machines.

Here it is obvious that the main source of the machine compliance are its joints, providing connections between the moving platform with a spindle motor on it and the machine's base parts.

Therefore, the development of new parallel kinematics machine architectures and the development of joints with high stiffness parameters is the topical task.

\section{Design of machine-tool joint}

In a previously published work [1] an original three-axis parallel kinematic machine-tool structure [2] presented (Fig. 1).

The machine includes three kinematic chains, each of which is a parallelogram formed by two rods oriented one above the other (4) connecting the vertical movement drive carriage (3) and the moving platform (2) through joints $(5,6)$.

The original structure of this machine provides both increased rigidity against cutting forces torque due to the triangular design of one of the links, and resistance to

* E-mail address: bulat-mart@yandex.ru ISSN: 1791-2377 (c) 2015 Kavala Institute of Technology. All rights reserved. overturning of the spindle due to the vertical arrangement of parallelogram links.

This structure has at least two variants. In the first variant the rods of chain I are connected with the carriage through Hooke's joints, and with a moving platform through cylindrical joints with horizontally oriented axes. Rods of II and III chains are connected both with the carriages and the moving platform through universal Hooke's joints with their leading axes arranged vertically (Fig. 2).

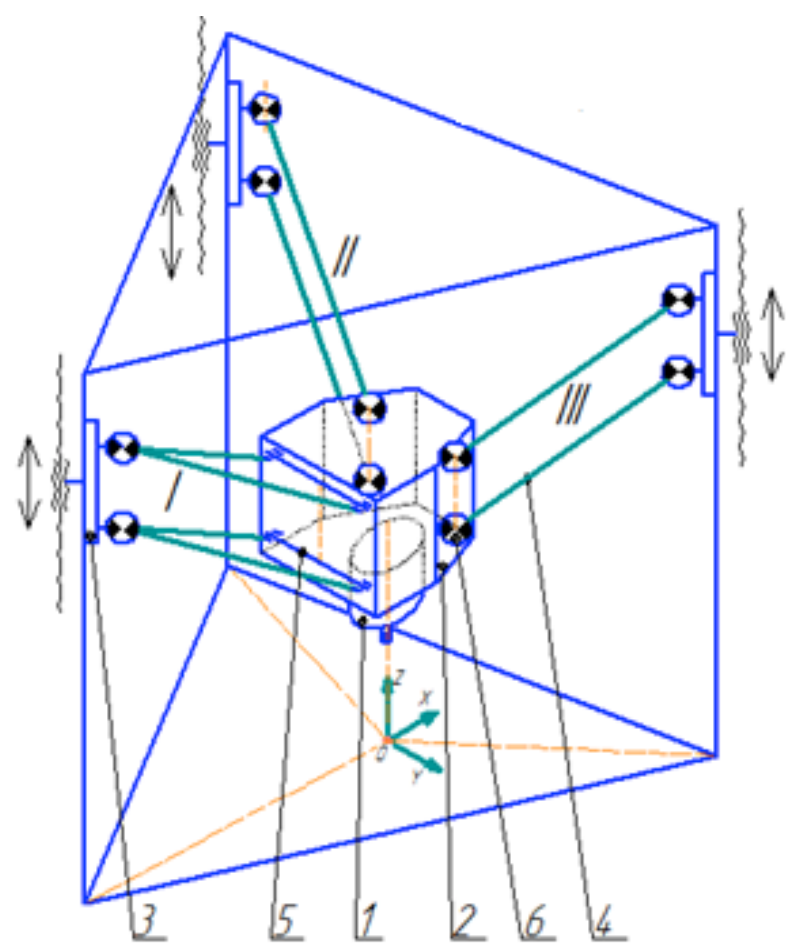

Fig. 1. PKM machine tool structure. 1 - milling spindle; 2 - moving platform; 3 - carriage; 4 - rod; 5 - cylindrical joint; $6-$ Hook's joint 


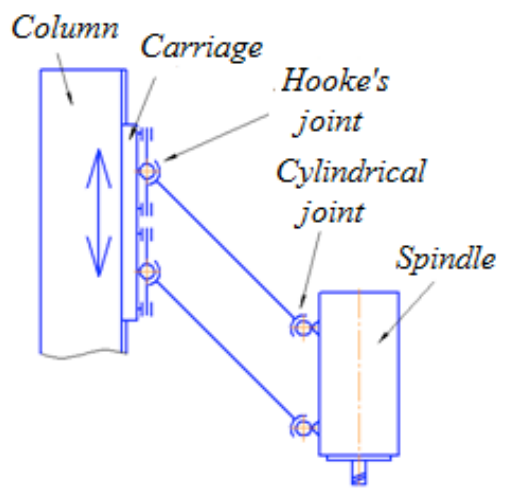

(a)

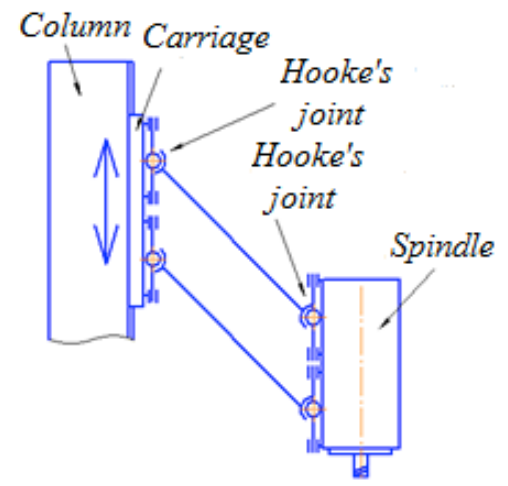

(b)

Fig. 2. Structure's kinematic chains scheme $a$ - chain I; $b$ - chains II and III
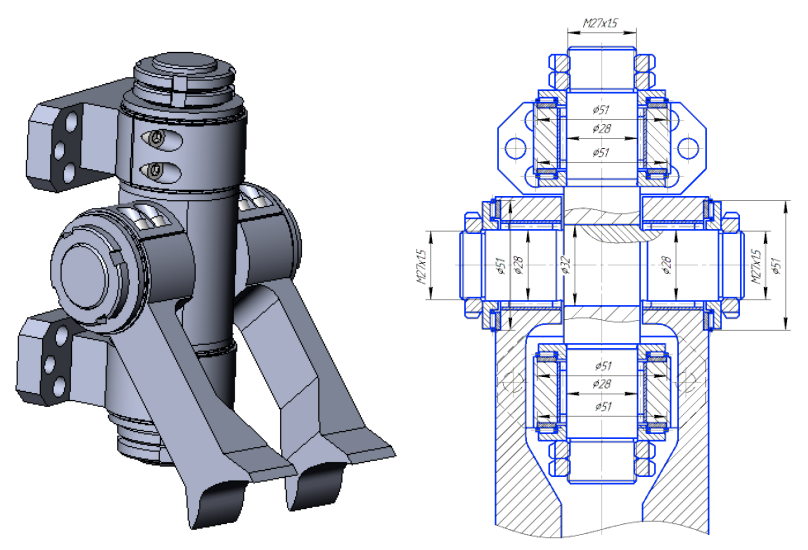

Fig. 3. Hook's joint design.

This structure sets a number of requirements to meet for Hooke's joint design: the limitation on the length of the supporting hinge axis which is defined by the height of the carriage and operating angles of at least $\pm 30^{\circ}$.

The developed design of a Hooke's joint meeting these specifications is shown in Figure 3. The joint design's feature is the use of needle bearings mounted with adjustable preload.

In the second structure variant (Fig. 4) the Hooke's joints mounted on the carriages are replaced by spherical rolling joints (Fig. 5)

A spherical joint presented in fig. 5 has been specially designed for parallel kinematics mechanisms [3], including milling machines [4].

Using spherical joints allows us to arrange Hooke's joints of II and III chains mounted on the movable platform so that their leading rotation axes are oriented horizontally.
Therefore, a compact and highly stiff design of a Hooke's joint with wide range of rod inclination angles can be used.
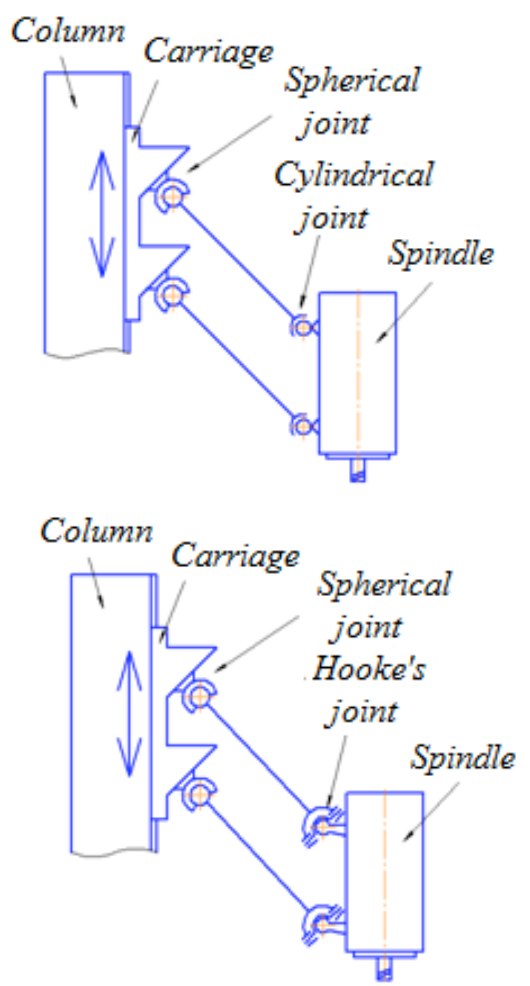

(a)

(b)

Fig. 4. Scheme of kinematic chains with spherical joints a - chain I; $\mathrm{b}$ - chains II and III

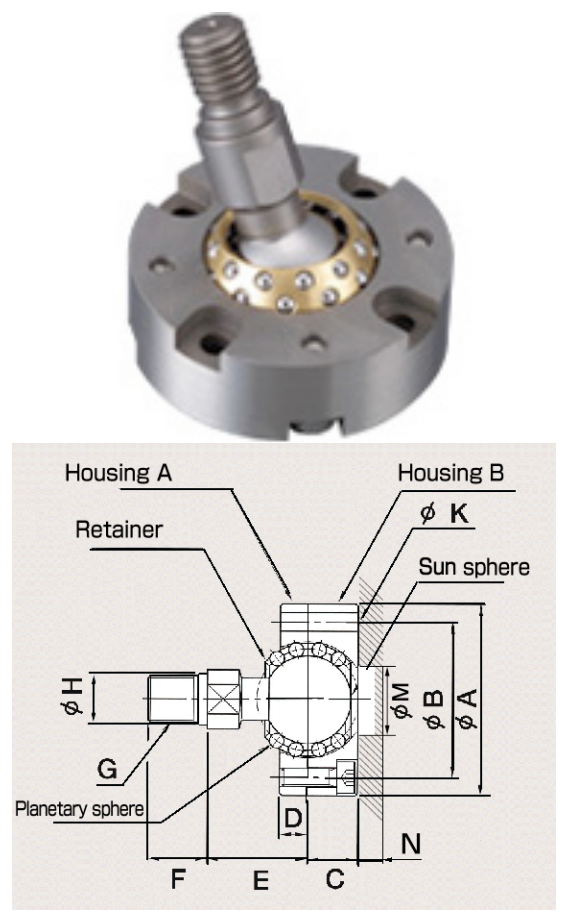

Fig. 5. Spherical rolling joint.

In addition, the spherical joint, having a low friction coefficient, removes the presence of bending stresses in rods. 
However, eventually, a key feature of the machine is its stiffness, when the final structure is selected it is necessary to make a comparative assessment of the spherical joint stiffness and Hooke's joint stiffness.

In the proposed Hooke's joint design radial needle roller bearings with an outer ring (I-CK 283524 GOST $4060-78$ ) and thrust needle roller bearings without rings (AK $35 \times 52 \times 2$ GOST 26676-85 ) are used (fig. 6). Geometry parameters of these bearings are shown in Table 1.

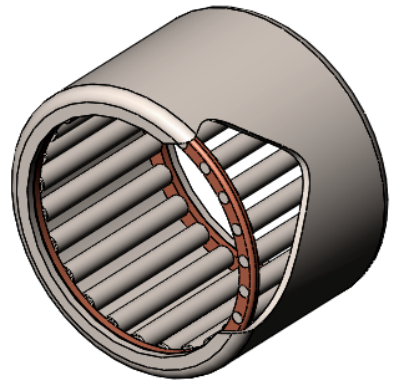

(a)

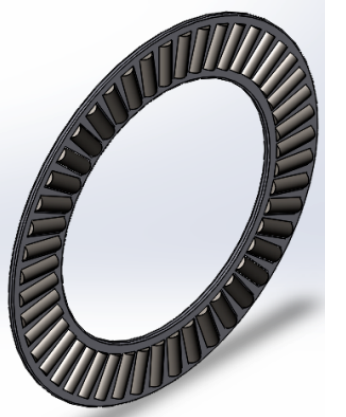

(b)
Fig. 6. Needle roller bearings a - radial; b - thrust.

$\underline{\text { Table 1. Bearings geometry parameters }}$

\begin{tabular}{l|c|c}
\hline & Radial bearing & Thrust bearing \\
\hline Inner diameter & $28 \mathrm{~mm}$ & $35 \mathrm{~mm}$ \\
Outer diameter & $35 \mathrm{~mm}$ & $52 \mathrm{~mm}$ \\
Needle diameter & $2,5 \mathrm{~mm}$ & $2 \mathrm{~mm}$ \\
Needle length & $19,8 \mathrm{~mm}$ & $5,7 \mathrm{~mm}$ \\
Number of needles & 25 & 47 \\
\hline
\end{tabular}

To reduce the computational time of Hooke's joints modeling it is necessary to calculate the stiffness of the bearings, so that they can be represented as equivalent spring connectors. For analytical calculation of bearings stiffness based on Hertz theory, the method proposed by Palmgren in [5] is used. The radial stiffness value of the bearing I-CK 283524 GOST $4060-78$ under the load of $1000 \mathrm{~N}$ obtained to be $k_{r}=2313886 \mathrm{~N} / \mathrm{mm} \approx 2.31 \cdot 10^{3} \mathrm{~N} / \mathrm{um}$.

Axial stiffness of the bearing AK $35 \times 52 \times 2$ GOST 26676-85 under the load of $1000 \mathrm{~N}$ obtained to be $k_{r}=1550363 \mathrm{~N} / \mathrm{mm} \approx 1.55 \cdot 10^{6} \mathrm{~N} / \mathrm{um}$.

Figure 7 shows the results of direct bearings modeling using finite element analysis with SolidWorks Simulation $(\mathrm{F}=1000 \mathrm{~N})$.

Modeling calculated the following results: radial stiffness of I-CK 283524 GOST 4060-78 bearing was $k=1000 \mathrm{~N} / 0.373 \mathrm{um}=2.681 \cdot 10^{6} \mathrm{~N} / \mathrm{um}$; axial stiffness of AK $35 \times 52 \times 2$ GOST 26676-85 bearing was $k=1000 \mathrm{~N} / 0.572 u m=1.748 \cdot 10^{6} \mathrm{~N} / \mathrm{um}$.

As it can be seen, the stiffness values of bearings obtained with the FEM modeling are similar to those obtained with the analytical calculations based on Hertz theory. Knowing the stiffness values of these bearings, they can be represented as equivalent spring connectors with the numerical values of their stiffness to create an equivalent model. This approach would significantly reduce the joints model calculation time. When selecting the stiffness values of spring connectors, bearings stiffness values were taken to be equal to the average value of the results obtained analytically calculations and numerically (Table 2).
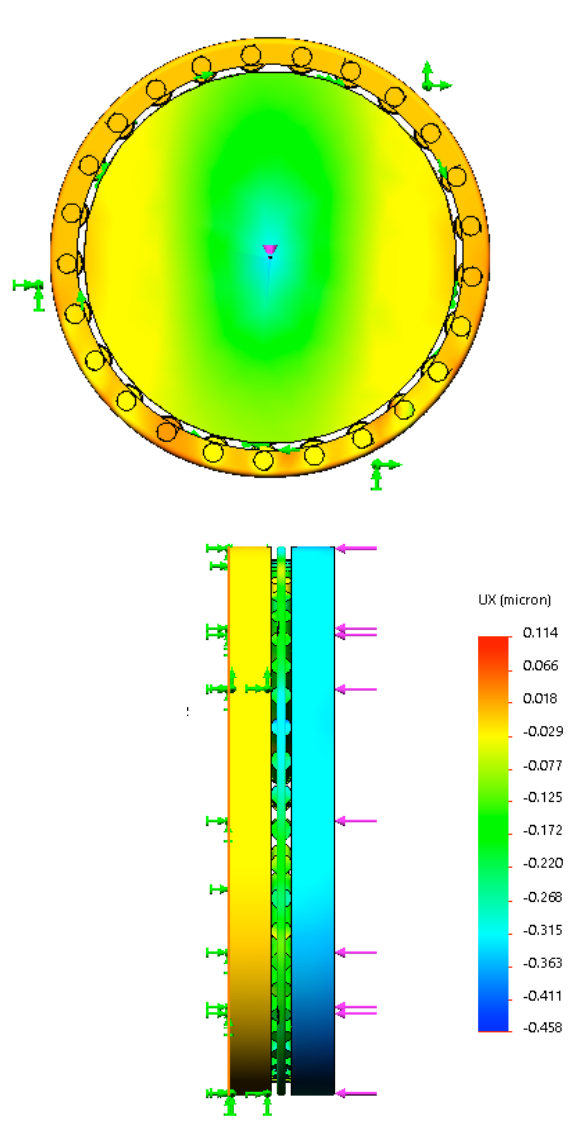
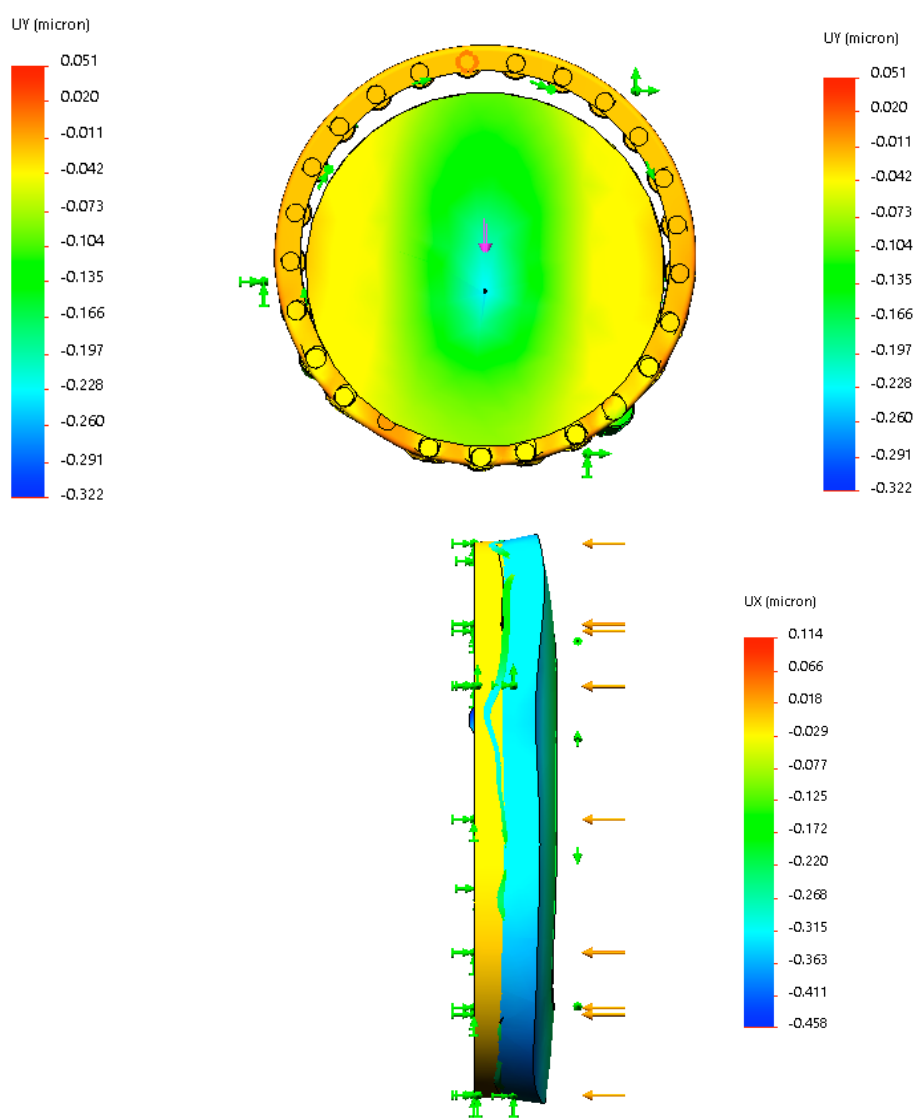

Fig. 7. Diagrams of elastic displacement of the bearing axis $a$ - radial bearing; $b$ - thrust bearing. 
Table 2. Bearings geometry parameters

\begin{tabular}{c|c|c|c|c}
\hline \multirow{2}{*}{ Bearing type } & $\begin{array}{c}\text { Calcula- } \\
\text { tion } \\
\text { method }\end{array}$ & $\begin{array}{c}\text { Compu- } \\
\text { tational } \\
\text { time }\end{array}$ & $\begin{array}{c}\text { Displace } \\
\text { ment } \\
\text { value, } \\
\text { um }\end{array}$ & $\begin{array}{c}\text { Stiffness } \\
\text { value, } \\
\text { N/mm }\end{array}$ \\
\hline \multirow{4}{*}{$\begin{array}{c}\text { I-CK 283524 } \\
\text { GOST 4060- } \\
\text { 78: }\end{array}$} & $\begin{array}{c}\text { Numerical } \\
\text { modeling }\end{array}$ & $\begin{array}{c}13 \mathrm{~min} \\
18 \mathrm{sec}\end{array}$ & 0.373 & $2.681 \cdot 10^{6}$ \\
\cline { 2 - 5 } & $\begin{array}{c}\text { Modeling } \\
\text { with spring } \\
\text { connectors }\end{array}$ & $23 \mathrm{sec}$ & 0.402 & $2.488 \cdot 10^{6}$ \\
\hline \multirow{3}{*}{$\begin{array}{c}\text { AK 35x52x2 } \\
\text { GOST 26676- }\end{array}$} & $\begin{array}{c}\text { Numerical } \\
\text { modeling }\end{array}$ & $03 \mathrm{sec}$ & 0.572 & $1.748 \cdot 10^{6}$ \\
\cline { 2 - 5 } & $\begin{array}{c}\text { Modeling } \\
\text { with spring } \\
\text { connectors }\end{array}$ & $01 \mathrm{sec}$ & 0.609 & $1.643 \cdot 10^{6}$ \\
\hline
\end{tabular}
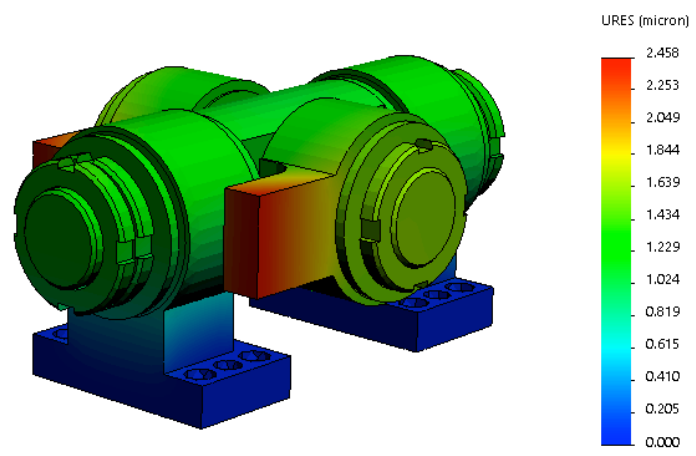

Table 3. Bearings geometry parameters

\begin{tabular}{c|c|c|c}
$\#$ & Angle, deg & $\begin{array}{c}\text { Rod's displacement under the } \\
\text { load of 1000 N, um }\end{array}$ & $\begin{array}{c}\text { Stiffness, } \\
\text { N/um }\end{array}$ \\
\hline 1 & 0 & 2.458 & 406.8 \\
3 & 90 & 2.395 & 417.5 \\
\hline
\end{tabular}

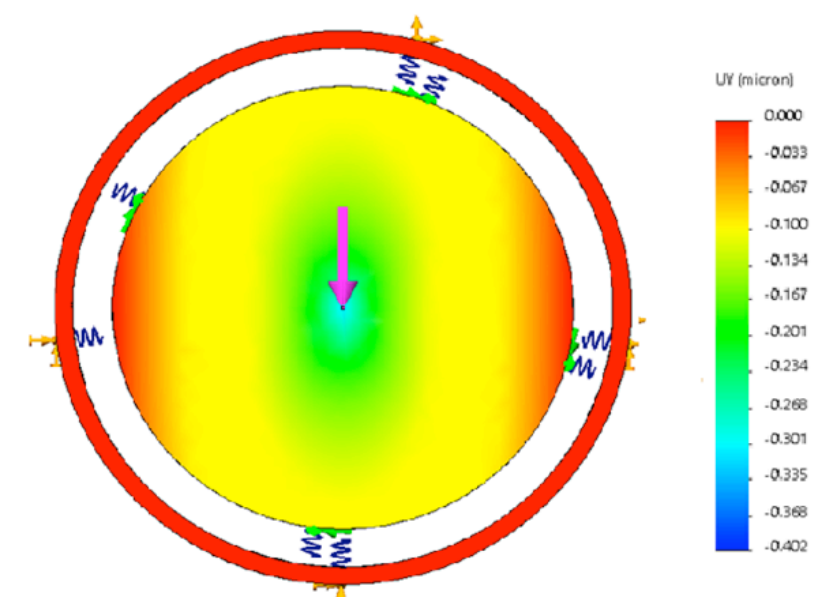

L.

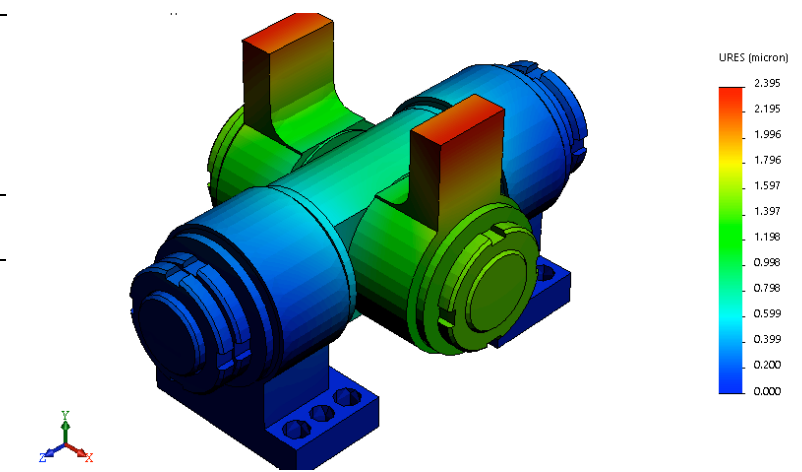

Fig. 9. Joints rod displacement diagrams
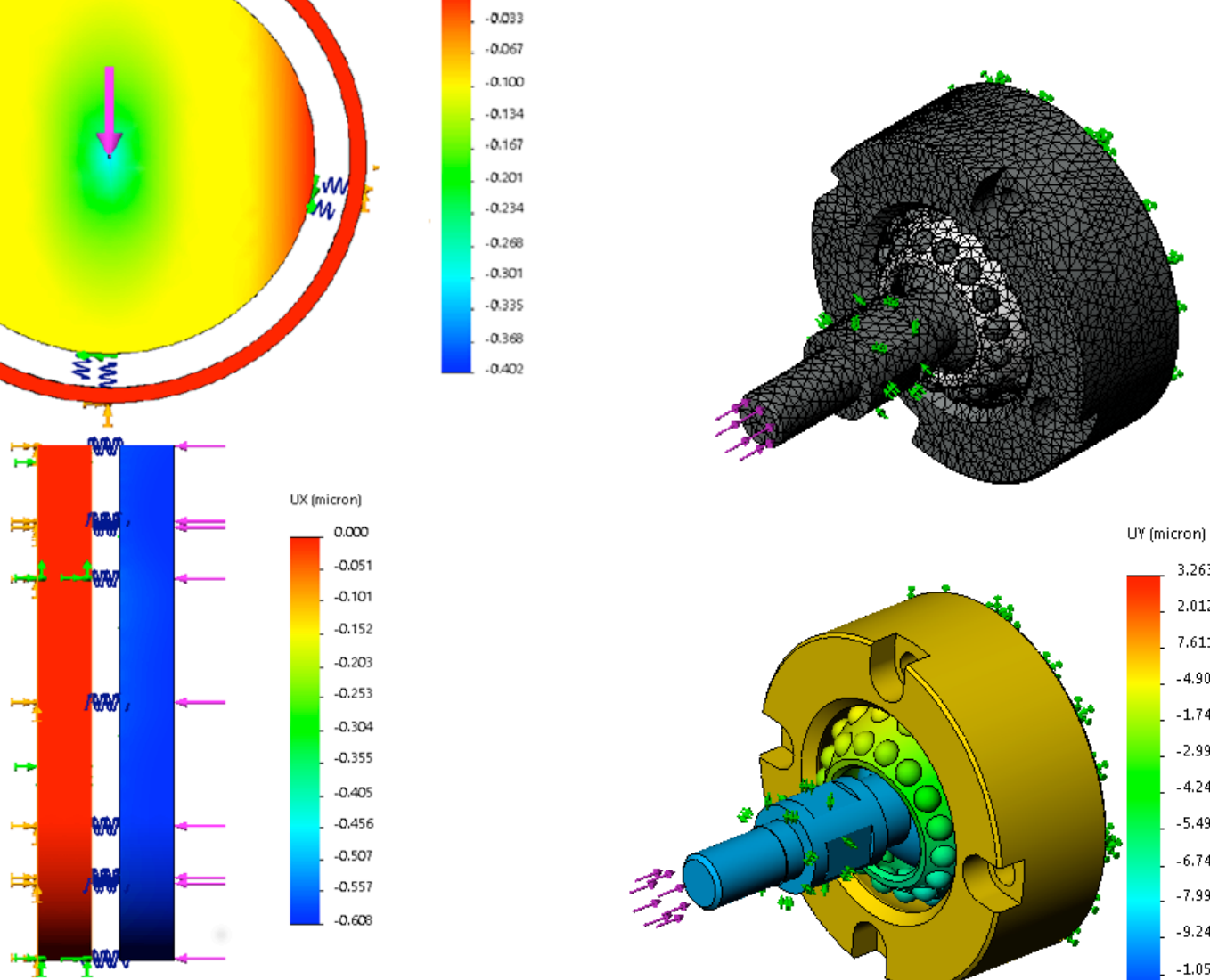

Fig. 8. Modeling of the bearings as equivalent spring connectors: a - radial bearing I-CK 283524 GOST 4060-78

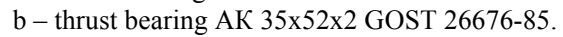
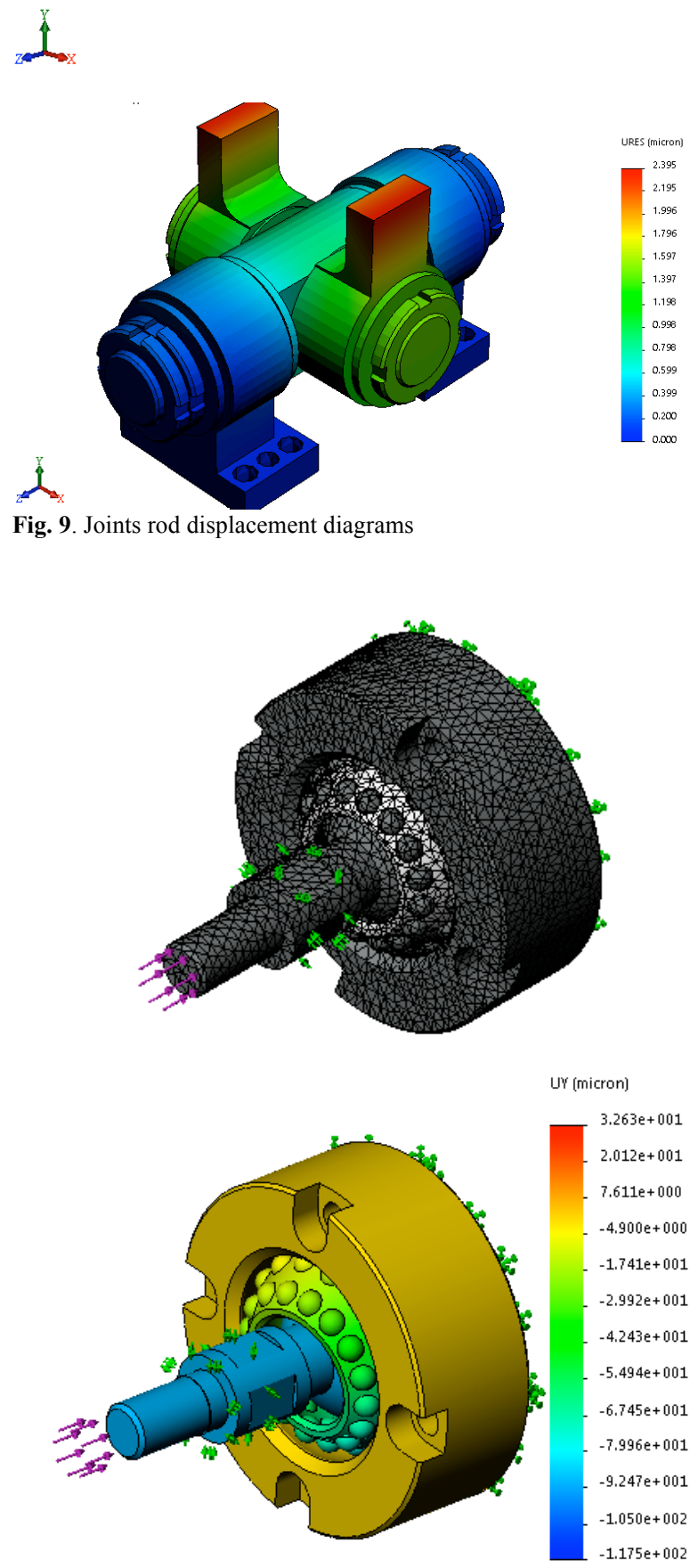

a

$\mathrm{b}$

Fig. 10. Spherical rolling joints modeling

a - FEM model; $b$ - Diagram of displacements under the loads 
Figure 8 shows the results of the modeling with spring connectors.

For radial bearing the distributed normal stiffness of equivalent spring connectors placed on concentric cylindrical faces was $2.01 \cdot 10^{12} \frac{\mathrm{N} / \mathrm{m}}{\mathrm{m}^{2}}$.

For thrust bearing the resulting normal stiffness of equivalent spring connector on the flat faces was

$$
1.642 \cdot 10^{9} \frac{N}{m}
$$

Based on these data a model of Hooke's joint design with bearings, presented in the form of equivalent spring connectors was constructed. Rod displacement values for two variants of their angular orientation were calculated (Fig. 9 a, b). The obtained values are shown in Table 3 .

For spherical joint stiffness analysis a finite element model with a fine mesh was developed (Fig. 10 a). The compliance of the spherical rolling joint was modeled for the central load application case of $1000 \mathrm{~N}$. The resulting displacement diagram is shown in Figure $10 \mathrm{~b}$. The resulting stiffness of the spherical rolling joint reached $8.5 \mathrm{~N} / \mathrm{um}$.
Thus, the calculated spherical joints stiffness is more than 40 times lower than the calculated Hooke's joint stiffness with needle bearings. Consequently, it is not suitable to use spherical joints in drilling/milling/boring type machines with parallel kinematics.

\section{Conclusions}

The paper presents an original design of Hooke's joint based on needle roller bearings. The bearing stiffness modeling is presented and the correctness of its representation as equivalent spring elements is explored. Comparing the spherical joint with the Hooke's joint shows that the spherical joint has a much lower stiffness, which indicates that it is inappropriate to use spherical rolling joints in drilling/milling/boring type machines with parallel kinematics.

\section{Acknowledgments}

These studies were carried out with the financial support of the Ministry of Education and Science of the Russian Federation within the state order (design part) № 9.712.2014/K

\section{References}

[1]. Akmaev O.K., Enikeev B.A., Nigmatullin A.I., "Static Stiffness Modeling of a Novel PKM-Machine Tool Structure", Journal of Engineering Science and Technology Review, vol.7, Issue 5, pp. 12-17, 2014.

[2]. Akmaev O.K., Enikeev B.A., Usupov A.F., Parallel kinematics based on multipurpose machine tool configuration. Russian patent application № 2013131749 1981-01. [In Russian]

[3]. Spherical Rolling Joint SRJ series. Production Guide. [URL: http://www.hephaist.co.jp/e/pro/ball.html]

[4]. Design of a New meso-Milling Machine Tool (mMT), Computer Integrated Manufacturing,

[URL: http://cimlab.mie.utoronto.ca/parallel-kinematicsmechanism/deisng-of-new-mmt/]

[5]. L. Molnár, K. Váradi, G. Bódai, P. Zwierczyk, L. Oroszváry, "Simplified modeling for needle roller bearings to analyze engineering structures by FEM", Periodica Polytechnica Mechanical Engineering, vol.1, no.54, pp. 27-33, 2010. 